\title{
Safety, efficacy and acceptability of medical abortion with mifepristone and misoprostol in Nepalese women
}

\author{
Veena Shrivastava \\ Department of Obstetrics \& Gynaecology \\ Nepal Medical College, Jorpati
}

\begin{abstract}
Unsafe abortion is a major health issue. Therefore safe abortion services which is effective. acceptable and techniquely easy to perform should be available.

Aim- To confirm effectiveness, side effects, safety and patient satisfaction with medical termination of early pregnancy.

Methods- It was a prospective study 150 women who were less than 63 days pregnant and consented for medical termination of pregnancy were given! $200 \mathrm{mg} 0$ Mefepristone orally and 48 hrs later 800 micro gram Misoprostol was inserted vaginally. They were followed up in 14 days. Bleeding, pain G.I symptoms any other side effects were recorded. Abortion was complete or not was confirmed clinically and by USG. Failure and success was documented depending upon need for surgical evacuation.

Results- The success rate with this regime was $92.6 \%$ and failure rate was $7.3 \%$. There were no major side effects with Mifepristone. The average bleeding after misoprostol insertion was 10 days and $80 \%$ women had more bleeding than normal period. All of them had pain. Only 13.3\% needed analgesic. women (96\%) were satisfied with the method.
\end{abstract}

Conclusion- combination of mifepristone and misoprostol is a safe and effective of early pregnancy

Keywords- medical termination, pregnancy, mifepristone, misoprostol.

\section{Introduction}

Termination of pregnancy has been practiced since the time immemorial. About 26 million pregnancies are terminated legally throughout the world and 20 million are terminated illegally which causes about 78,000 deaths every year. ${ }^{1}$ Thirteen percent world wide ${ }^{1}$ and $5 \%{ }^{2}$ of total maternal death in Nepal is due to induced abortion. After $11^{\text {th }}$ amendment of Muluki Ain in September 2002, under certain circumstances abortion has become legal in Nepal.

Suction evacuation is the most widely used method for first trimester abortion since 1960's. Invention of prostaglandin and its analogues in $1970 \mathrm{~s}$ and mifepristone in 1980s has revolutionized the method of abortion. Because of these medicines abortion has become easier and safer. France was the first country to license this combination for early first trimester abortion. At present combination of mifepristone and misoprostol is being used for both first and second trimester abortion in many countries. It is highly recommended for early first trimester pregnancy.

\section{Aim}

The objective of this study is to confirm effectiveness, side effects, safety and client satisfaction of medical abortion performed with use of mifepristone and misoprostol combination for early first trimester abortion in Nepalese women.

Correspondence

Dr. Veena Srivastava, $M D$

Associate Professor, Nepal Medical College, Jorpati, Kathmandu, Nepal.

Email:veenashrivastava@gmail.com 


\section{Method}

It was a prospective study of 150 women, who opted for medical abortion in a private clinic. All clients who requested for termination of early pregnancy were given option between medical and surgical method of abortion. Mode of action, advantage and disadvantage of both the methods were explained to them. When they agreed for medical abortion, an informed consent was taken. Gestational age was confirmed with ultra sonogram (USG).

Inclusion criteria:

All clients with upper limit of gestation 63 days by ultra sonogram

Exclusion Criteria: History of Bronchial asthma Suspected ectopic pregnancy Long term oral steroid therapy Severe anaemia

\section{Treatment protocol used for medical abortion}

\section{a. Day -1}

1. Mifepristone $(200 \mathrm{mg})$ - one tab was given to the client to be swallowed under supervision.

2. She was instructed not to take any food for next two hours.

3. She was advised to attend the clinic after 48 hours of ingestion of mifepristone.

4. Informations were given on possible side effects. She was requested to write down or inform anything abnormal happening to her.

b. Day - 3

1. 800 microgram misoprostol (200 microgram tabfour tabs) inserted high into the posterior fornix of vagina.

2. Allowed to rest for half an hour.

3. Possible side effects were explained. Client requested to write down or inform anything abnormal happening to her.
4. Discharged home after half an hour of insertion of misoprostol with emergency contact number.

5. Inj Anti D given, if mother is Rh negative .

6. Family Planning (FP) counseling was done.

7. Time arranged for follow up in two weeks.

\section{c. Two weeks follow up}

1. Asked about bleeding per vagina and passage of product of conception (POC).

2. Any problems regarding heavy bleeding, pain abdomen, gastrointestinal disturbance, and rise in temperature were recorded.

3. Clinical examination and USG performed to confirm complete abortion

4. Family Planning counseling was done. Clients were encouraged to adopt FP measure then and there.

\section{d. Emergency Management}

If the client complains of heavy bleeding or there was evidence of incomplete abortion, emergency suction evacuation was performed.

In case of persistent significant bleeding at two weeks follow up but without evidence of incomplete abortion clinically and by USG, then another dose of misoprostol 200 micro grams with a course of antibiotic was given. Follow up was arranged in one week in such cases. Suction evacuation was performed in cases of persistence of bleeding.

\section{Results}

25(18.5\%) clients were unmarried. Nulliparous $42(28 \%)$; Primipara 46 (30.6\%); multipara (2-4) 60 (40\%) and grandmultipara $2(1.3 \%)$ This shows that the majority of clients were multiparous. Eighty nine had previous normal delivery, fifteen had one and two had two previous caesarean sections.

Three women were Rh negative, two had small fibroid and one was suffering from idiopathic thrombocytopenic purpura (ITP).

Table I. Age distribution

\begin{tabular}{lrrcccc}
\hline \multirow{2}{*}{$\begin{array}{c}\text { Age } \\
(\mathrm{yrs})\end{array}$} & Number & Percentage & \multicolumn{5}{c}{ Parity } \\
\cline { 4 - 7 } & & & Nulliparous & Primipara & Multipara (2-4) & Grandmultipara \\
\hline$<19$ & 4 & 2.6 & 3 & 1 & - & - \\
$20-34$ & 141 & 94.0 & 39 & 45 & 56 & 1 \\
$>35$ & 5 & 3.3 & - & - & 4 & 1 \\
\hline Total & 150 & 100.0 & 42 & 46 & 60 & 2 \\
\hline
\end{tabular}

Age of the clients ranged between 17 to 42 years. 
Table 2. POG at the time of request for MTP

\begin{tabular}{ccc}
\hline $\begin{array}{c}\text { Duration of pregnancy } \\
\text { (weeks) }\end{array}$ & Number & Percentage \\
\hline 4 & 16 & 10.6 \\
5 & 60 & 40.0 \\
6 & 56 & 37.3 \\
7 & 18 & 12 \\
\hline Total & 150 & 100 \\
\hline POG: & period of gestation \\
MTP: & \\
& medical termination of pregnancy \\
\hline
\end{tabular}

Table 3. Side effects of mifepristone/ misoprostol

\begin{tabular}{lll}
\hline Side effects & $\begin{array}{l}\text { Mifepristone } \\
\text { Number (\%) }\end{array}$ & $\begin{array}{l}\text { Misoprostol } \\
\text { Number (\%) }\end{array}$ \\
\hline No complaints & $40(26.6)$ & \\
Nausea & $75(50)$ & \\
Vomiting & $20(13.3)$ & 0 \\
Diarrhoea & 0 & 0 \\
Loss of appetite & $55(36.6)$ & - \\
Weakness & $110(73.3)$ & - \\
Rise in temp & $\mathrm{X}$ & $4(2.6)$ \\
Headache & $2(1.3)$ & $150(100)$ \\
Pain abdomen & 64 & $20(13.3)$ \\
Need for analgesic & & $150(100 \%)$ \\
(1-3 tabs paracetamol) & \\
Bleeding p/ $*$ & $25(16.6)$ & \\
Expulsion of POC & $1(0.6)$ & \\
(36 hrs later) & & \\
\hline
\end{tabular}

*brownish discharge-slight bleeding usually after 24 hrs

Table 4. Duration of pain abdomen

\begin{tabular}{ccc}
\hline Duration (days) & Number & Percentage \\
\hline 1 & 78 & 52.0 \\
2 & 28 & 18.6 \\
3 & 23 & 15.3 \\
4 & 1 & 0.6 \\
5 & 15 & 10.0 \\
6 & 6 & 4.0 \\
7 & 1 & 0.6 \\
\hline Total & 150 & 100.0 \\
\hline
\end{tabular}

Out of 150 clients, $84(56 \%)$ were using natural method of contraception (coitus interruptus). 60(40\%) were not using any contraceptive. 4 clients were using oral contraceptive pills and one had intrauterine contraceptive device which dropped out and, one was taking depo provera

\section{Amount of Bleeding}

In four cases it was lighter than menstrual period lasting for 2-3 days. It was heavier than menstrual period on first two days then like normal period in 55 cases. Bleeding was same as menstrual period for one week in 26 cases. Those cases that had bleeding more than one week had heavy flow for one or two days followed by slight bleeding only. None of the cases needed blood transfusion. $80 \%$ women had bleeding which was more than menstrual period.

\section{Expulsion of product of conception (POC)}

45 clients $(30 \%)$ identified expulsion of POC within 112 hours of insertion of misoprostol. One client identified POC after $36 \mathrm{hr}$, one on third day and one on $9^{\text {th }}$ day. Only one client expelled POC $36 \mathrm{hrs}$ after ingestion of mifepristone. Others noticed blood clots only.

\section{$\underline{\text { Failure of medical termination }}$}

Continuation of pregnancy occurred in one case. Surgical evacuation was needed in 11 cases all of whom were more than 6 weeks pregnant and multiparous. In one case suction evacuation was needed $8 \mathrm{hrs}$ after insertion of misoprostol, because of history of heavy bleeding. Three cases showed some POC in uterine cavity at two weeks follow up therefore immediate evacuation was done.

In one case, evacuation was done on fourth day for pain and heavy bleeding.

Second insertion of misoprostol was needed in 10 cases for persistence of significant bleeding at two weeks follow up. 5 of them needed evacuation later, as bleeding did not stop.

\section{Client Satisfaction}

Ninety six percent women were satisfied. Even those who needed evacuation were satisfied Reason for satisfaction was avoidance of surgery. The evacuation they needed if at all was easy and quick. One client did not like it because of self involvement and feeling of guilt. One did not like it because of more pain abdomen and prolonged bleeding. She came back in six months requested again for medical TOP. 
Table 5. Duration of bleeding per vagina

\begin{tabular}{ccc}
\hline Duration (weeks) & Number & Percentage \\
\hline$<1$ & 85 & 56.6 \\
$1-2$ & 43 & 28.6 \\
$2-3$ & 20 & 13.3 \\
$3-4$ & 2 & 1.3 \\
\hline Total & 150 & 100.0 \\
\hline
\end{tabular}

Mean duration of bleeding was 10 days

\section{Discussion}

Mifepristone and misoprostol are the drugs increasingly used for early first trimester abortion. They are approved by WHO and licensed in about 150 countries. Methotrexate and Misoprostol either in combination or alone have also been tried for early first trimester abortion with varying degree of success $(84-96 \%){ }^{2}$ Side effects and failure rate are more in this combination compared to mifepristone and misoprostol combination. The present study supported most of the findings of other reports. Most important is failure rate. Any case that required surgical evacuation due to continuation of pregnancy, incomplete abortion, persistence of bleeding or clients request because of pain or bleeding was considered as failure. In this study the failure rate was $7.3 \%$. The failure rates quoted by other studies are between $5-8 \%{ }^{4-14}$

139 cases out of 150 cases had complete abortion (Success rate 92.6\%).

The story of the client who had continuation of pregnancy was unique. According to the report, earlier the medical termination used, there are more chances of success ${ }^{14}$. This lady had routine pregnancy test as a part of routine medical test. Pregnancy test was positive though there was no history of amenorrhea. On USG no gestation sac was seen and as there was no pain or tenderness in pelvic region ectopic pregnancy was ruled out. Suction evacuation was done later as viable pregnancy was seen at two weeks follow up.

Regarding side effects, mifepristone did not give any serious side effects. Few clients had vomiting. One client vomited within two hours of ingestion, mifepristone was not repeated. She had complete abortion after insertion of misoprostol. Most of the women had prolonged and heavy bleeding (mean 10 days). A comparative study of bleeding pattern of early termination of pregnancy by surgical method and by medical method using mifepristone and misoprostol done on 212 women ${ }^{15}$, found slightly longer duration of bleeding in medical group than this study. The mean duration of bleeding in medical group was 14 days whereas it was 5 days in surgical group done by MVA. Days of spotting were about 10 days, which was similar in both the groups.

Gastro intestinal symptoms were almost absent after misoprostol insertion. Four clients did have rise in temperature. This was assumption of the clients as temperature was not recorded.

A comparative study of surgical and medical early termination of pregnancy done in 932 women up to 63 days was done by J.J. Child et. al. ${ }^{16}$ There was no age and parity difference between both the groups. The incidence of complete abortion was $90.2 \%$ with medical method and $94.5 \%$ with surgical method. Complete abortion rate decreases significantly with increase in parity.

Many women $83.3 \%$ had complete abortion following medical treatment, whereas the chance of having complete abortion in such women was $97.7 \%$ with surgical method. This is supported by Cochrane Database Syst Rev. 2005. ${ }^{17-18}$ In this study all clients with failure of termination had more than one children. But two grand multi para had complete abortion.

In spite of high failure and more side effects almost all of the clients were satisfied with the medical method because it was not invasive and they could avoid surgery.

\section{Conclusion}

Medical method of abortion using combination of mifepristone (200 mg orally) followed by misoprostol ( 800 micro gram vaginally) after $48 \mathrm{hrs}$ is a safe and effective way of termination of early pregnancy for those who do not want any invasive method. It can be recommended that all women seeking termination of early pregnancy should be given informed choice between medical and surgical methods.

\section{References}

1. Safe abortion, Technical \& policy Guidance for health system WHO, 2003.

2. Comprehensive Abortion care Services, Reference Manual, His Majesty Government, Ministry of health and population, Department of Health Services, Family Health Division, Nov 2004.

3. Wiebe E, Dunn S, Guilbert F et al. Comparison of abortion induced by methotrexate followed by misoprostol. Obstet Gynaecol 2002 May 99; $5 \operatorname{Pt}(1): 813-9$. 
4. KulierR,Gulmezoglu AM, Hofmevr G.J.et al. Medical method for first trimester abortion Cochrane Database Syst Rev. 2004(2):CD003037

5. Basu R, GundlachT, TaskerM. Mifepristone and misoprostol for medical termination of pregnancy: the effectiveness of a flexible regimen. Journal of Family Planning and Reproductive Healthcare. July 2003; 29 (3): 139-141(3).

6. Thong KJ, Baird DT. Induction of abortion with mifepristone and misoprostol in early pregnancy. Br J Obstet Gynaecol 1992 Dec; 99(12):1004-7.

7. Honkanen H, PiaggioG, Hertzen $\mathrm{H}$ et al. WHO multinational study of three misoprostol regimens after mifepristone for early medical abortion. BJOG 2004 July; 11(7): 715-25.

8. Jain JK, Dutton C, Harwood B. A prospective randomized, double blind, placebo-controlled trial comparing mifepristone and vaginal misoprostol to vaginal misoprostol alone for elective termination of early pregnancy. Hum Repro.2002 Jun;17(6):1477-82.

9. Cheung W, Tang OS, Lee SW et al. Pilot study on the use of sublingual misoprostol in termination of pregnancy up to 7 weeks gestation. Contraception 2003 Aug; 68(2):97-9.

10. Tang OS, Chan $\mathrm{CC}, \mathrm{Ng} \mathrm{EH}$ et al. A prospective randomized placebo-controlled trial on the use of mifepristone with sublingual or vaginal misoprostol for medical abortions less than 9 weeks gestation. Human Reprod 2003 Nov;18 (11):2315-8
11. Hamoda H, Ashok PW, Dow J. A pilot study of mifepristone in combination with sublingual or vaginal misoprostol for medical termination of pregnancy up to 63 days gestation. Contraception 2003 Nov; 68(5): 335-8.

12. Hamodah, Flett GM. Medical termination of pregnancy in early first trimester. J Fam Plann Reprod Health Care. 2005 Jan;31(1):10-4.

13. Honkanen H, Piaggio G, Hertzen $\mathrm{H}$ et al. WHO multinational study of three misoprostol regimen after mifepristone for early medical abortion. BJOG 2004 Jul(7): 715-25.

14. Goodyear SF, Knowles A, Masters J. First Trimester medical termination of pregnancy: an alternative for New Zealand women. Aust NZJ Obstet Gynaecol 2006 Jun; 46(3):193-8.

15. RCOG Guidelines for care of Women requesting termination of pregnancy 2004.

16. Davis A, Westhoff C, De NonnoL. Bleeding Pattern after early abortion with mifepristone and misoprostol or manual vacuum aspiration. J Am Med Womens Assoc 2000; 55(3 Suppl):141-4.

17. Henshaw RC, Naji SA, Russell IT et al. Comparison of medical abortion with surgical vacuum aspiration; women's preference and acceptability of treatment. BMJ 1993 Sept 18; 307(6906): 714-7.

18. Say L, Kulier R, Gulmezoglu M et al. Medical versus surgical method for first trimester termination of pregnancy. Cochrane databases Rev. 2005; (1): CD003037 